\title{
Deep Geoelectric Structure and Its Relation to Seismotectonics of the Saurashtra Region, Western India
}

\author{
D. N. Murthy ${ }^{1}$, K. Veeraswamy ${ }^{1}$, T. Harinarayana ${ }^{1,2}$ \\ ${ }^{1}$ CSIR-National Geophysical Research Institute, Hyderabad, India \\ ${ }^{2}$ Presently at BS Abdur Rahaman Crescent Institute of Science and Technology, Chennai, India \\ Email: director.cers@crescent.education
}

How to cite this paper: Murthy, D.N., Veeraswamy, K. and Harinarayana, T. (2020) Deep Geoelectric Structure and Its Relation to Seismotectonics of the Saurashtra Region, Western India. Open Journal of Earthquake Research, 9, 181-200. https://doi.org/10.4236/ojer.2020.92011

Received: January 31, 2020

Accepted: March 24, 2020

Published: March 27, 2020

Copyright () 2020 by author(s) and Scientific Research Publishing Inc. This work is licensed under the Creative Commons Attribution International License (CC BY 4.0).

http://creativecommons.org/licenses/by/4.0/

\begin{abstract}
The Saurashtra Peninsula and its adjoining regions covered by Deccan Traps (DT) are one of the important parts of the Indian continental lithosphere with interesting geophysical anomalies, tectono-thermal evolution since the Mesozoic times. Knowledge on the deep structure beneath these formations is important for understanding the seismo-tectonics of the region. This region has gained importance after the occurrence of a major earthquake (7.9 Mw) north of Saurashtra, namely Bhuj earthquake during 2001. It is also observed that Saurashtra region has experienced several earthquake swarms limited to small regions. Accordingly, it is important to investigate the deep structure of the Saurashtra region from seismotectonics point of view. In our study, magnetotelluric results of the deep crustal structure along five NS oriented traverses are presented. The five traverses are-Halvad-Rohisa (HR), Sapar-Iswaria (SI), Mota Dahinsara-Bamagadh (MB), Jodiya-Jamkhandorna (JJ) and VavBeraja-Devda (VD). The total length of these 5 traverses is about 670 $\mathrm{km}$. The derived deep geoelectric structure is also compared and correlated with gravity data to get more confidence on the derived results. The 2-D geoelectric section has delineated anomalous high conductivity structure at places extending from $20 \mathrm{~km}$ to about $40 \mathrm{~km}$. From the spatial correlation, anomalous high conductive structure derived from MT data with intense localized seismic activity is an interesting observation. In the present study, the results of magnetotelluric studies along with other geophysical results are presented.
\end{abstract}

\section{Keywords}

Magnetotelluric, Seismotectonics, Geoelectric Structure, Earthquakes, Electrical Conductivity 


\section{Introduction}

At the western continental margin of India, a prominent feature-Saurashtra Peninsula (SP) - formed as a unique feature is known to have experienced different faces of stretching, rifting and uplifting during the geological past [1] [2]. The rifting pattern is believed to be developed initially from the north and sequentially extended to the south around the Saurashtra peninsula. The boundaries of the SP are the Kachchh rift towards the north and the Cambay rift towards the east with the other two sides occupied by the Arabian Sea. It is believed that the tectonics of the Saurashtra peninsula is controlled by three major Precambrian trends-Dharwar trend (NNE-SSW), Aravali-Delhi trend (NE-SW) and Satpura trends (ENE-SWS). The Aravalli trend cuts across the Cambay graben before entering SP. The major rifting events occurred in different geological periods from Gondwana in Late Jurassic or Early Jurassic after breaking up of the Indian landmass from Antarctica. The region is believed to be influenced by the thermo-tectonic events since the Mesozoic period due to the interactions of the Indian plate with Reunion plume. It is also believed that the massive volcanic eruption has occurred $65 \mathrm{Ma}$ due to this tectonic event from the studies of Courtillot [3]. The duration of the eruption might be less than $1 \mathrm{Ma}$. Due to shallow mantle in this region high thermal gradients are attributed. A huge pile of basalts has erupted during Upper Cretaceous Tertiary boundary and spread over more than 100,000 sq.km [4]. Such a large spread of basalts also covered the SP. Additionally, there are a few volcanic plugs exposed in SP towards the southeast and southwestern part (see Figure 1). This can be clearly seen in the form of locally elevated hill like structures and also manifested in the form of large circular gravity anomalies. It is also believed that due to interaction of Reunion plume with the Indian Plate, a triple junction has been formed with Cambay rift as one of the arms, the Narmada rift as another arm towards the east and the Kachchh rift towards the west. High heat flow $\left(67 \mathrm{~mW} / \mathrm{m}^{2}\right)$ is reported along the triple junction and could probably be due to the outburst and trace of the Reunion plume [5]. Towards the northeastern part of SP large pile of sediments belonging to Dhrangadhra and Wadhwan formations are reported. From paleo-river channel studies, it is believed that the exposed sediments might also be present below the trap cover of SP as these sediments are older than the exposed Deccan traps. Additionally, if we detect any deep seated intrusive structures, those locations can be considered as possible occurrence of future earthquakes as they might be reactivated due to tectonic forces.

It is in this context that magnetotelluric studies have been taken up to understand the seismotectonics of the region. Anomalous conductive features that exist in the upper and lower crustal depths can easily be mapped using the magnetotellurics method. Magnetotellurics is well known for probing the earth from shallow level to large depths of even $50-100 \mathrm{~km}$ from the observation of the natural variation of the electromagnetic signals. The details of data acquisition, processing and modeling procedures followed are described in Ph.D. thesis [6]. Here we discuss the importance of the results derived from the study from seis- 
motectonics point of view.

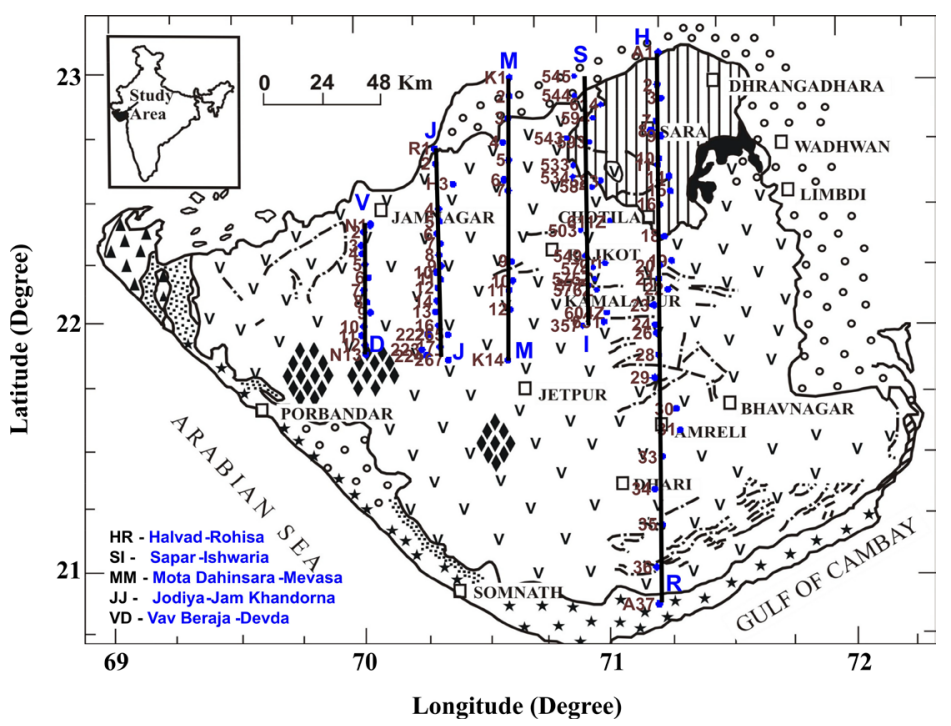

Figure 1. Location of magnetotelluric stations along 5 traverses, namely HR, SI, MB, JJ and VD shown on the regional geological map of Saurashtra region. V-indicates the Deccan Traps, o, * and vertical lines indicate the exposed sediments, cluster of diamond symbols are the volcanic plugs.

In short, in the present study, the results of magnetotelluric studies are presented along five traverses-HR, SI, MB, JJ and VD. In Figure 2 these five traverses are shown on regional gravity anomaly map of the region. In the following the subsurface section derived along these profiles is presented.

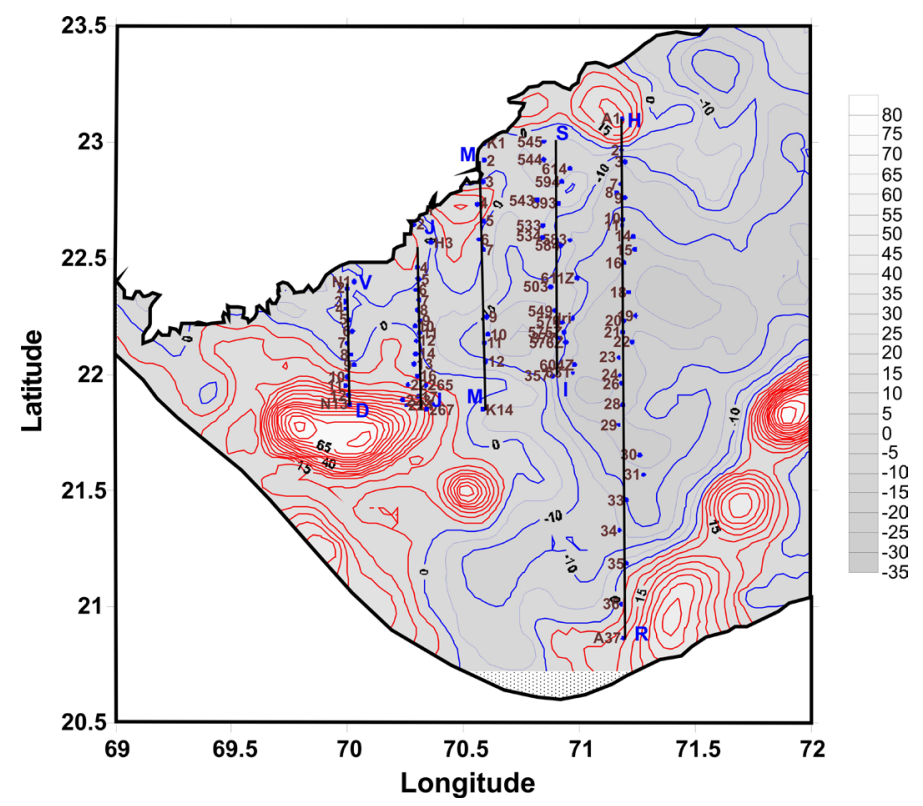

Figure 2. Five NS traverses shown on the regional gravity anomaly map. Five major closed group of contours-three towards the SE corner and two towards the western part-are the indication of the volcanic plugs in the region (modified Bouguer gravity anomaly map, 2006). 


\section{Magnetotelluric Studies}

\subsection{Geoelectric Section along the HR Traverse}

The shallow section derived along the HR (Figure 3(a)) traverse has shown a thin $(<250 \mathrm{~m})$ trap cover from Chotila to Jasdan (site A16 to A23) and sharply increases to about $1.5 \mathrm{~km}$ from Amreli and further south. The basement is about $1.5 \mathrm{~km}$ north of Sara (site A8) and increases to about $2 \mathrm{~km}$ further south from Chotila. From the resistivity section it is observed that the top layer of the basement with a thickness of half a kilometer is less resistive $(100 \mathrm{Ohm} \cdot \mathrm{m})$ as compared to the high resistive basement $(>2000 \mathrm{Ohm} \cdot \mathrm{m})$ below.

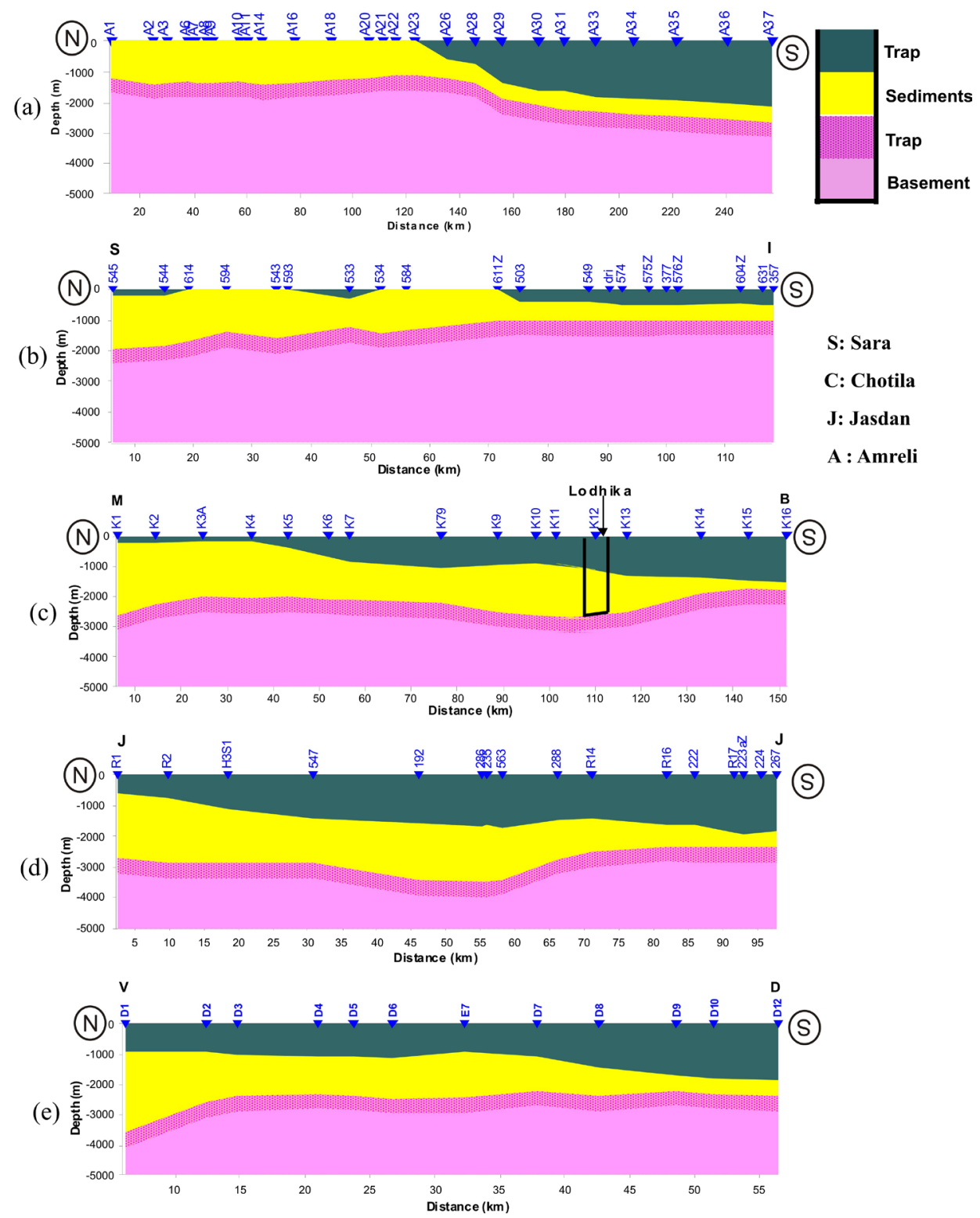

Figure 3. Shallow geoelectric section along five traverses, namely (a) HR, (b) SI, (c) MB, (d) JJ and (e) VD showing major geological units-trap, sediments and basement. In (c) drilled borehole location can also be seen. In general, the thickness of traps decreases from south to north along all the traverses. 
This can be interpreted as the presence of another layer of Deccan trap above the basement. Between the trap and the basement, conductive formations are clearly delineated all along the traverse with varying thickness of about $1.5 \mathrm{~km}$ from Sara to north and increases to about $2 \mathrm{~km}$ near Chotila and becoming thin or absent as we move from Jasdan further south. The deep geoelectric structure presented here (Figure 4) is a smoothed version giving more emphasis on correlation with geological formations. Thin steeply dipping conductive features are delineated at five locations along the traverse. This can be interpreted in terms of the possible existence of the crustal scale faults extending to mid-crustal depth levels $(>15 \mathrm{~km})$. These thin conductive features are bounded by high resistive $(>2000 \mathrm{Ohm} \cdot \mathrm{m})$ features. This can be interpreted as a block structure. Additionally, 3 prominent conductive features at mid crustal depth levels are seen below the Sara, Jasdan and south of Amreli region.

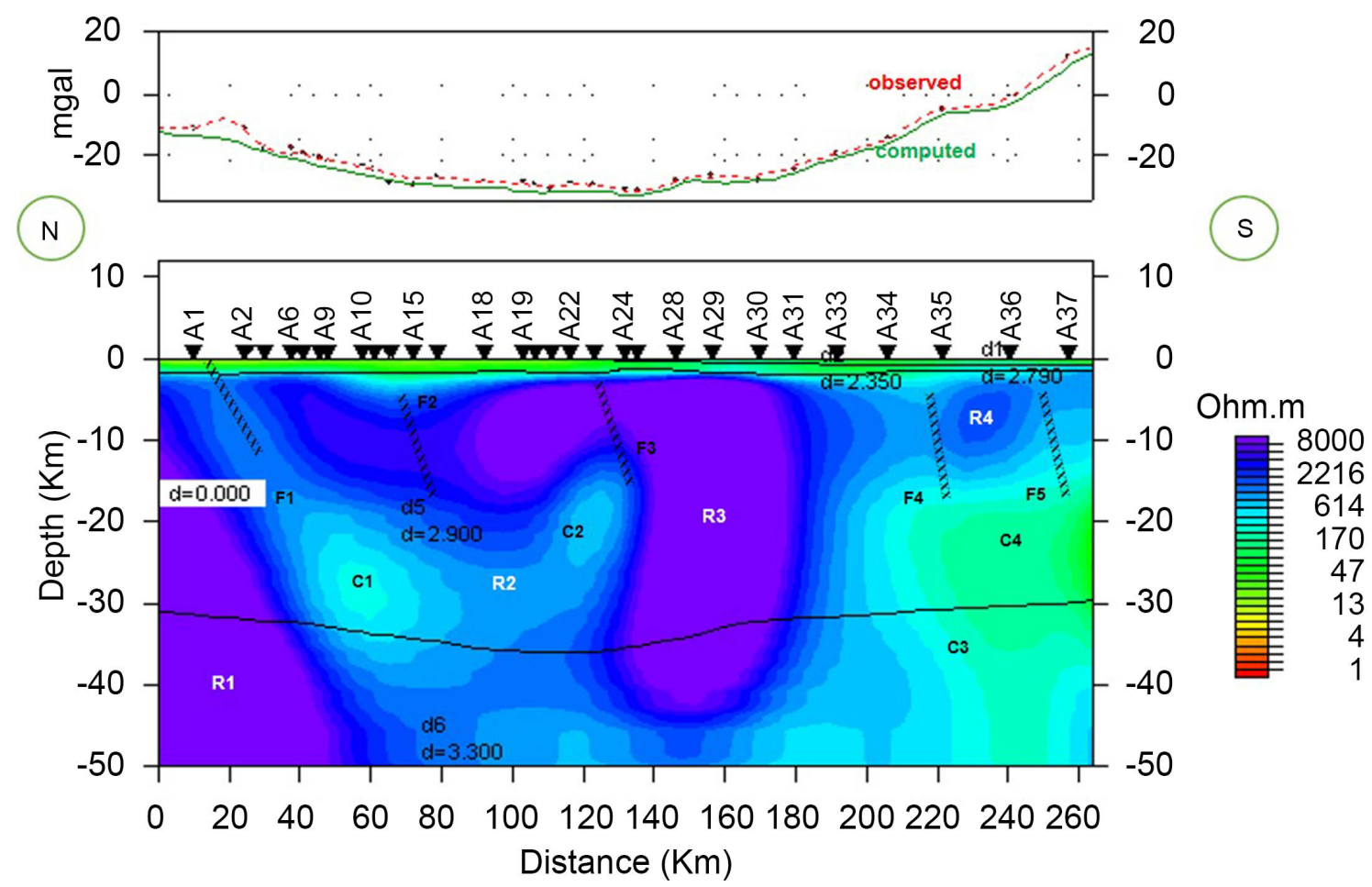

Figure 4. Deep geoelectric section along HR traverse along with regional gravity observed data and modelled response can be seen. C1 - C4 are conductors and R1 - R4 are resistors. Boundaries of the resistive formations, deep seated faults can be observed.

\subsection{Geoelectric Section along the SI Traverse}

The geoelectric section derived from 2-D modeling along SI traverse and the interpreted shallow geological section is presented in Figure $3(\mathrm{~b})$. The exposed trap cover is thin $(<500 \mathrm{~m})$ from south (site 357$)$ and maintains the same level towards north up to the site 503 located in the middle of the traverse. Further north, the trap cover is very thin $(<100 \mathrm{~m})$ or absent. The electrical basement depth is about $2 \mathrm{~km}$ towards the north and gradually reaches $1.5 \mathrm{~km}$ towards the 
south. The top layer of the basement is less resistive (100 Ohm $\cdot \mathrm{m})$ compared to the high resistive $(>2000 \mathrm{Ohm} \cdot \mathrm{m})$ bottom layer. As before this can be interpreted for the presence of the second layer of the basalts or mixture of basalts and sedimentary formations. The deeper geoelectric section from 0 to $50 \mathrm{~km}$ (Figure 5) shows two interesting conductive features, one near the sites 544,614 towards north and another near the site 611 in the middle of the traverse. This is interpreted as crustal scale fault features extending from the upper crust to mid crustal depths. They are separated by three resistive (>2000 Ohm $\cdot \mathrm{m})$ features R1, R2 and R3. The resistive feature can be interpreted as a block structure within the basement.

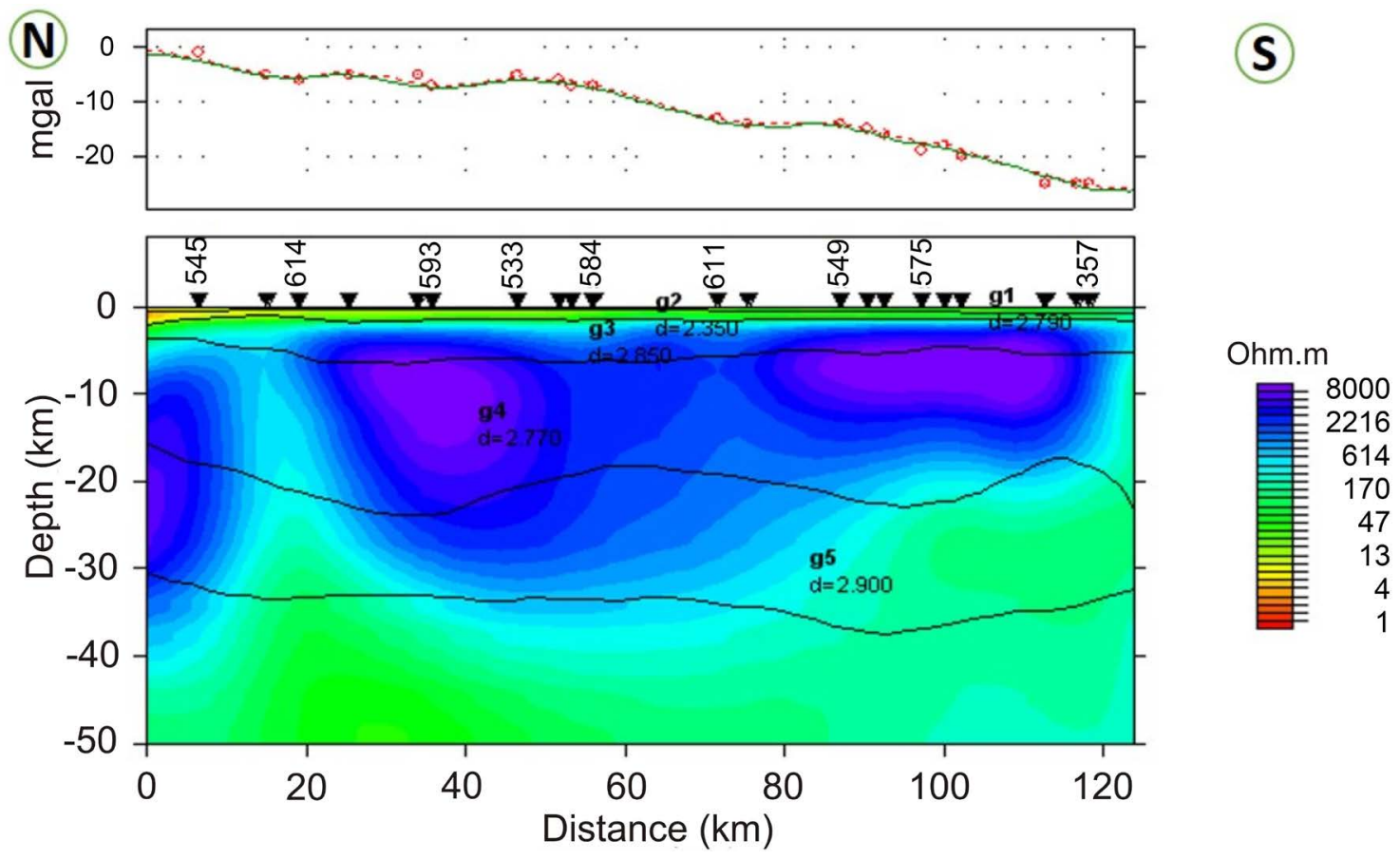

Figure 5. Deep geoelectric section along SI traverse along with regional gravity observed data and modelled response can be seen. Here four layers with varying density values required to match the observed gravity data.

\subsection{Geoelectric Section along the MB Traverse}

As before the smoothed geological section derived from shallow geoelectric section is presented in Figure $3(\mathrm{c})$. Thin trap cover $(<100 \mathrm{~m})$ can be seen below the sites $\mathrm{K} 1-\mathrm{K} 4$, which gradually increases to about $1 \mathrm{~km}$ below the site $\mathrm{K} 7$ until $\mathrm{K} 12$ and further increases to $1.5 \mathrm{~km}$ below the sites K13 to K16. The electrical basement depth is about $2.5 \mathrm{~km}$ towards north and gradually decreases to $2 \mathrm{~km}$ towards south. Between the trap and the basement, high conductive $(<20$ $\mathrm{Ohm} \cdot \mathrm{m}$ ) sedimentary formation is observed with a thickness of about $2.5 \mathrm{~km}$ towards north and gradually diminishes to $<500 \mathrm{~m}$ towards south as shown in Figure $3(\mathrm{c})$. In this traverse also, a layer with near about half a kilometer thickness and resistivity of $<300 \mathrm{Ohm} \cdot \mathrm{m}$ as compared to the layer below is observed. From the deep geoelectric section, thin conductive layers steeply dipping below 
the stations K3A and K10 separated by block like resistive structures as shown in Figure 6. Similar to earlier traverses these narrow conductive features are interpreted in terms of the presence of crustal scale faults extending from upper crust to mid crustal depths.

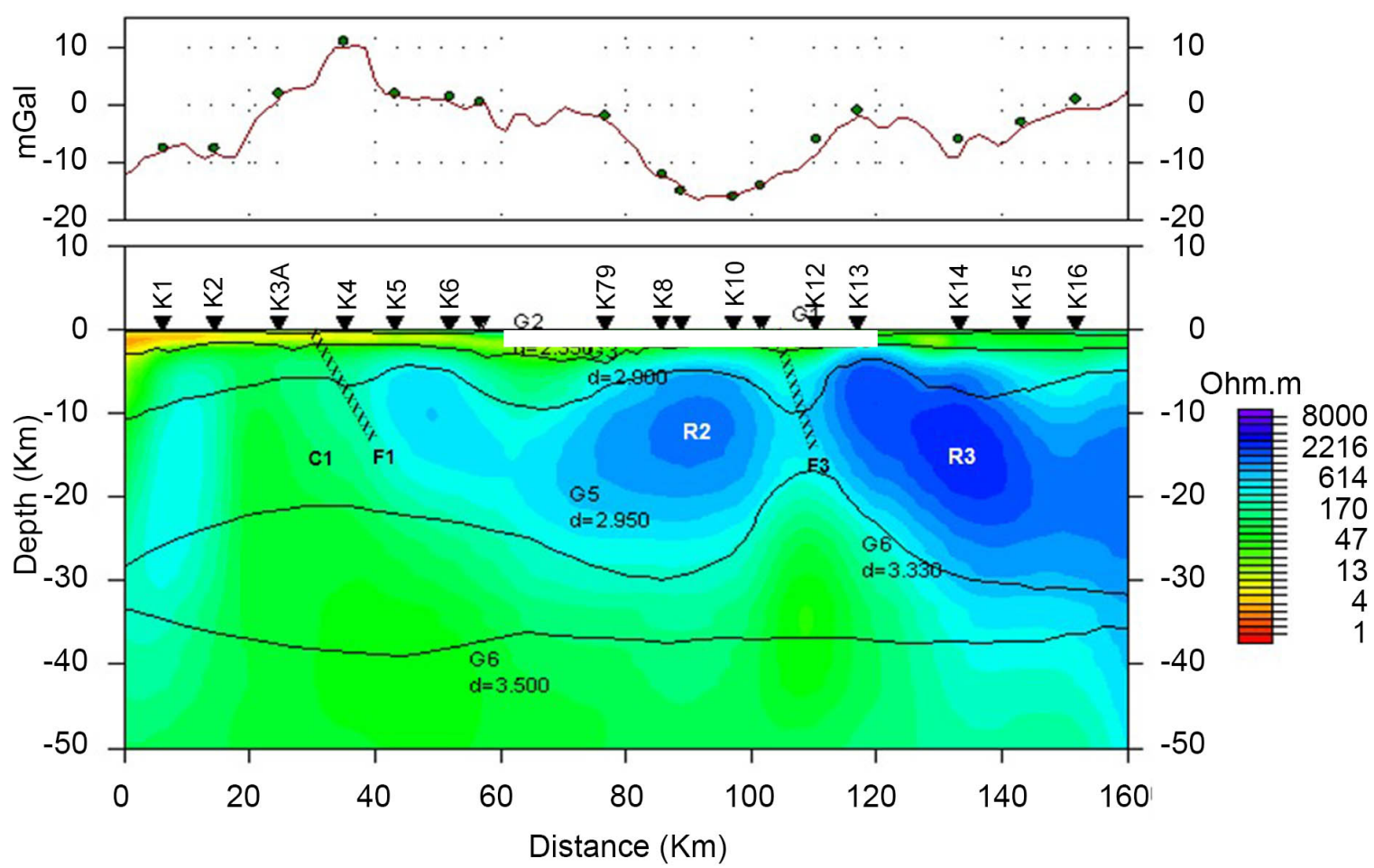

Figure 6. Deep geoelectric section along MB traverse along with regional gravity observed data and modelled response can be seen. As before a four layered model with varying density is required to match the gravity model response with the observed data. A deep seated fault is inferred near the K12 MT station.

\subsection{Geoelectric Section along the JJ Traverse}

The smoothed section presented in Figure 3(d) along the JJ traverse is based on the geoelectric section presented. The trap thickness seems to be thin $(500 \mathrm{~m})$ and increases to about $1.5 \mathrm{~km}$ near middle of the traverse and further increases to $2 \mathrm{~km}$ towards south at the end of the traverse. The electrical basement depth is about $2.5 \mathrm{~km}$ towards north increases to about $3 \mathrm{~km}$ in the middle of the traverse and reaches shallow depths of about $2.5 \mathrm{~km}$ at the end of the traverse towards south as shown in Figure 7. Similar to other traverses, above the electrical basement consists of $0.5 \mathrm{~km}$ thick and less resistive layer as compared to the underneath high resistive layer $(>1000 \mathrm{Ohm} \cdot \mathrm{m})$. The less resistive layer can be interpreted as before, the presence of second basaltic layer or a mixture of sediments and basalts. The deep geoelectric structure has thin and steeply dipping conducting features near the sites R2, 192, and R17 separated by high resistive features. A smoothed version of the shallow geoelectric section is presented in Figure 3(d). The high resistive features could be interpreted as block structures in the upper crust. 


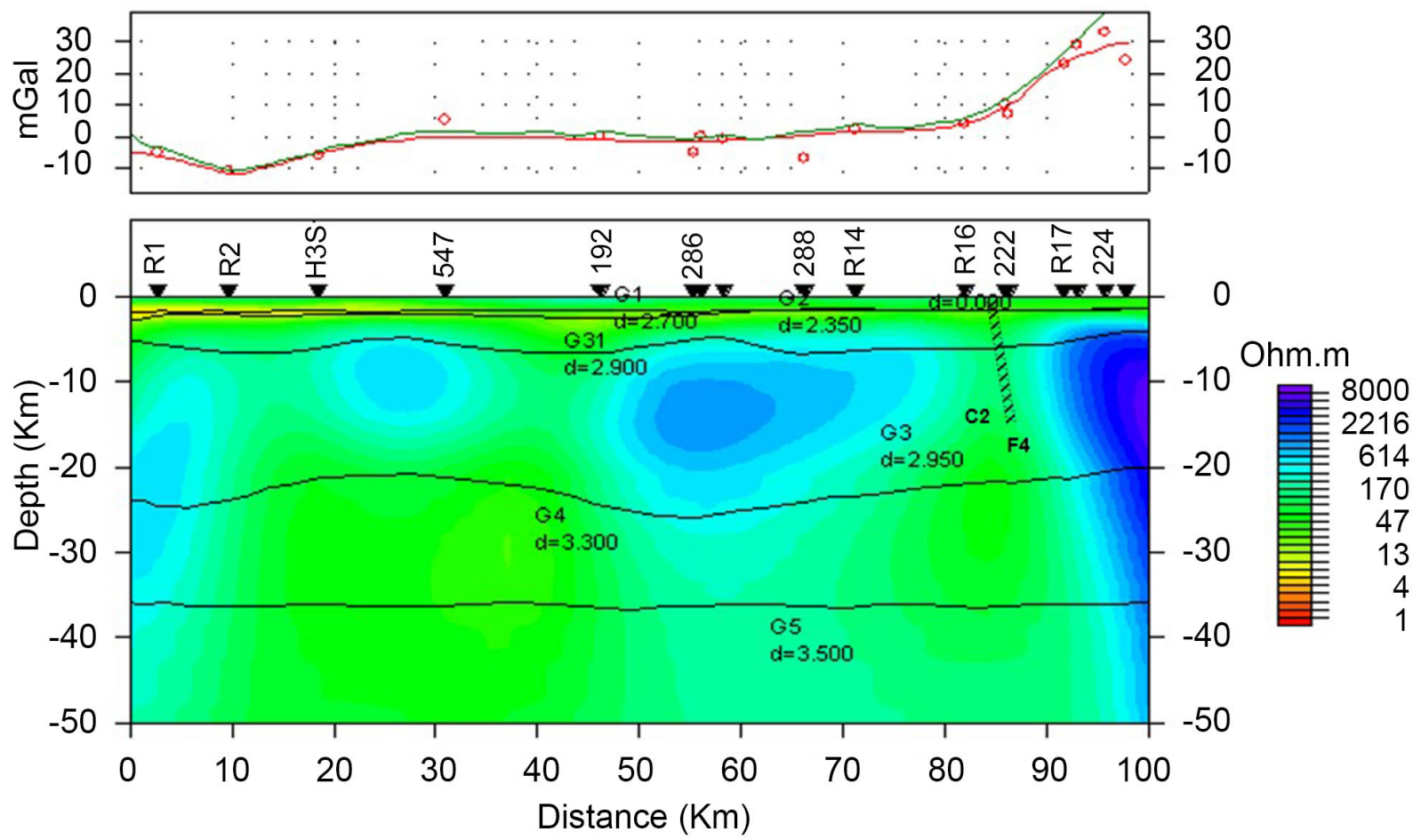

Figure 7. Deep geoelectric section along JJ traverse along with regional gravity observed data and modelled response can be seen. Good correlation of gravity high response with high resistive feature can be seen towards the southern part of the traverse. This could be due to the presence of volcanic plug buried below.

\subsection{Geoelectric Section along the VD Traverse}

The interpreted geoelectric section based on the derived shallow geoelectric section is presented in Figure 3(e). The exposed basalt layer is $1 \mathrm{~km}$ thick towards north and sharply increases from site D7 to further south to about $2 \mathrm{~km}$ towards the south. The electrical basement is about $3.5 \mathrm{~km}$ towards north gradually attains shallow depths of about $2.2 \mathrm{~km}$ towards south as shown in the figure. As before the electrical basement consists of two layers with a resistivity of 60 $\mathrm{Ohm} \cdot \mathrm{m}$ for the top layer and $>500 \mathrm{Ohm} \cdot \mathrm{m}$ for the bottom layer. The resistivity of the sediments is $<20 \mathrm{Ohm} \cdot \mathrm{m}$ along the traverse. Two steeply dipping thin features are observed below the sites D3 and D7, which can be interpreted for the presence of crustal scale faults. Unlike other geoelectric sections an anomalous high conductive feature, below the sites E7 is observed between resistive blocks (R1) towards north and another resistive block (R2) towards south from a depth of about $10 \mathrm{~km}$ onwards as shown in the geoelectric section (Figure 8). A smoothed section is shown in Figure 3(e). Interestingly, a significant observation is that the Mesozoic sediments are concentrated more on the northern side of the five traverses (with respect to A23, close to Jasdan of HR traverse) and gradually become thinner at depths towards the south. The geoelectric section is drawn lengthwise, starting from the HR traverse towards the north to VD towards the west for more clarity. A progressive trend in sedimentary thickness is perceived from north to west as well as thinning of the sediments to the south. 


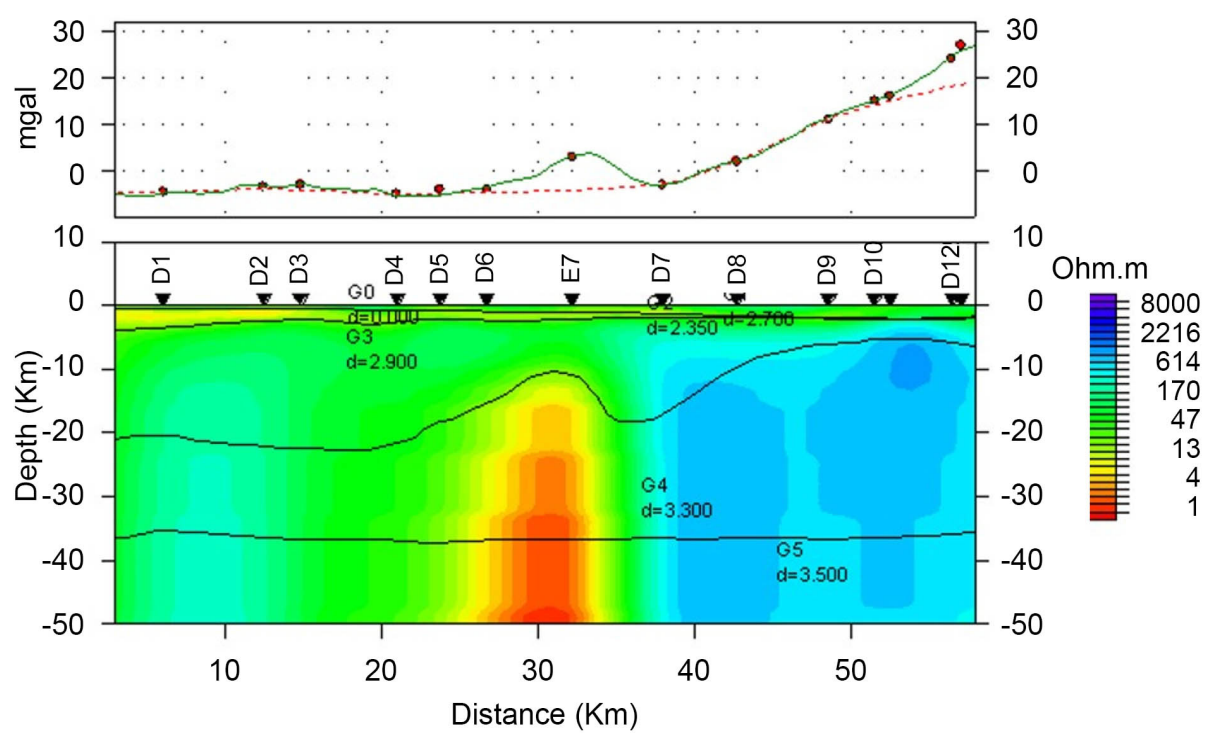

Figure 8. Deep geoelectric section along VD traverse along with regional gravity observed data and modelled response can be seen. Two resistive blocks towards the southern part of the traverse are co-relatable with gravity highs. Good correlation of intrusive conducting body near the station E7 with a gravity high is an indication of the presence of an intrusive body at mid-crustal depth.

In order to understand the trap thickness, sediment thickness and the basement depth features the results derived from all the above five traverses are combined to provide the regional distribution of the above formations; the details are described in the following: From the 2-D geoelectric section along the five profiles presented earlier in simplified shallow part of the geoelectric section described in the earlier section, the information available on all the individual profiles have been combined to provide a regional picture of the distribution of the geological formations namely the Deccan traps, the sediments and depth to the basement configuration (Figure 9).

\section{Thickness Maps}

\subsection{Deccan Trap Thickness Map}

Figure 9(a) provides the contour map showing the thickness of the Deccan trap formation. The contour map is based on the information available on the individual sections and restricting to the area between $21.50^{\circ}-23^{\circ}$ and $69.75^{\circ}-71.5^{\circ}$ longitude. The gridding, extrapolation and interpretation have been carried out using krigging method. As can be seen from Figure 9(a), the trap thickness is small towards the north and eastern part of the region and thick towards south and western part of the region. It is interesting to observe thick Deccan traps extending from the south towards west and northwest. From the pattern, it looks as though the Deccan trap volcanism might have traveled from southeast of the study region to northwest of the study region. This is in line with the occurrence of the volcanic plugs located towards south east as clearly shown in the form of large gravity circular highs of about $40-50 \mathrm{mGal}$ as shown in Figure 2. 
(a)
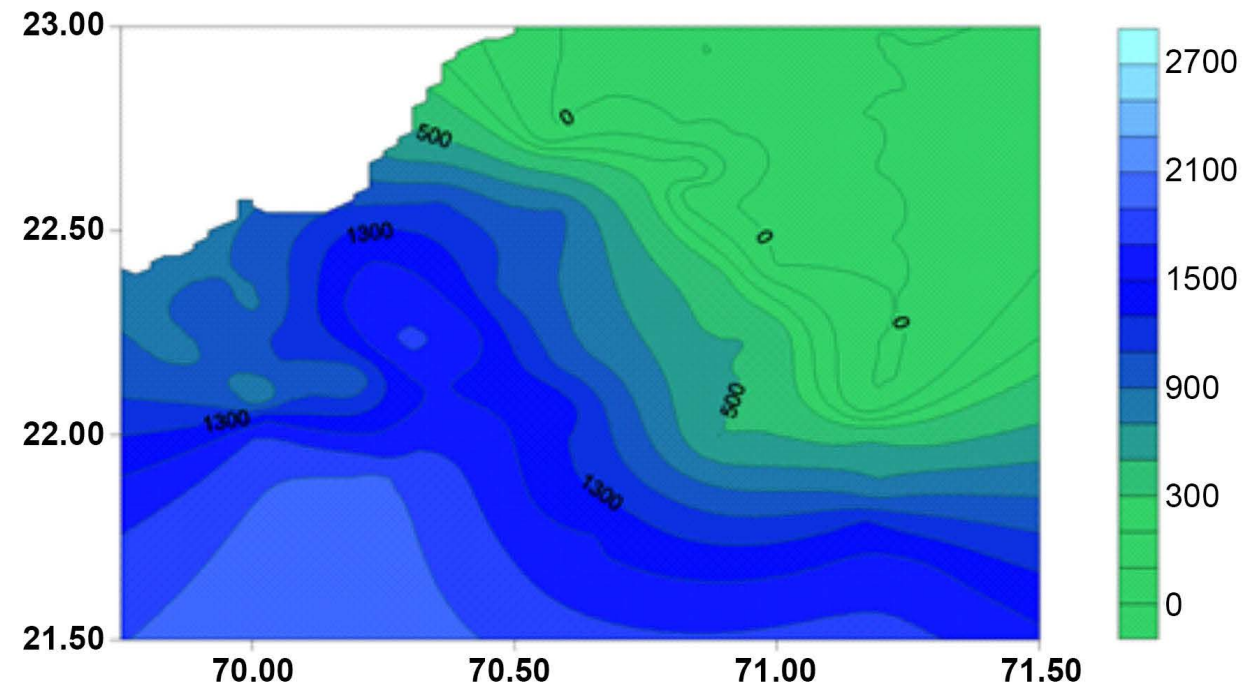

(b)

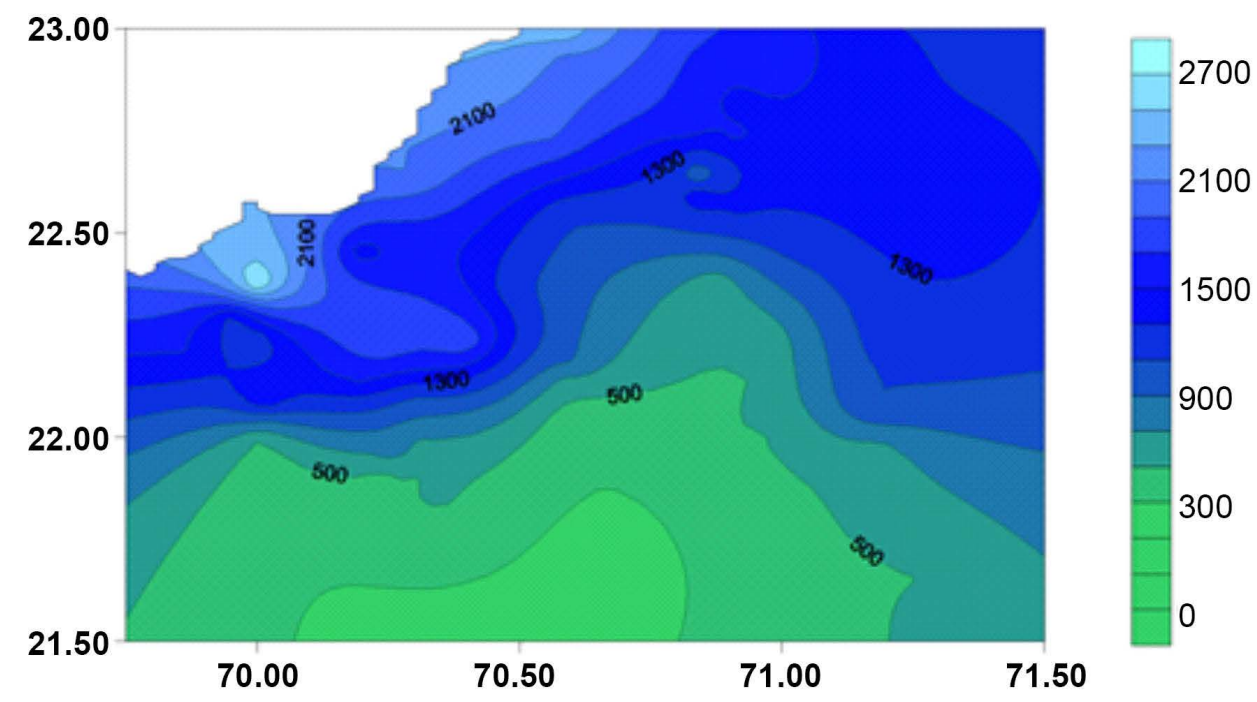

(c)

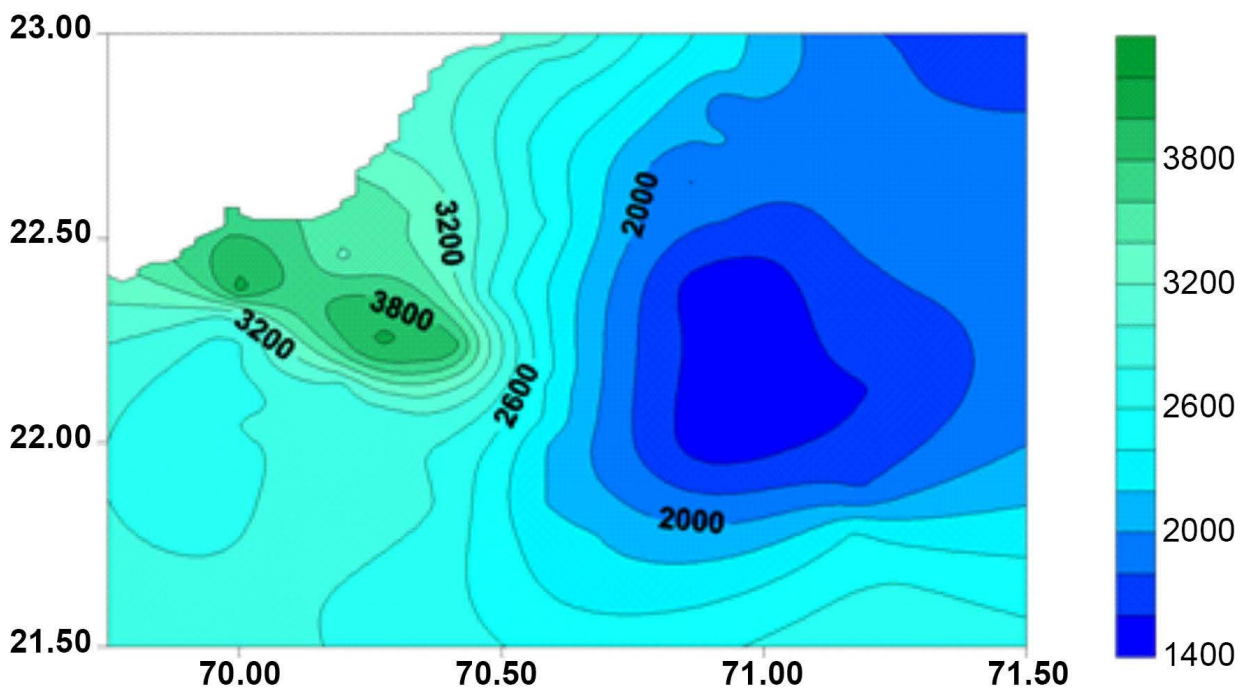

Figure 9. Major geological units derived from our study along five traverses have been contoured and presented here as contour maps-(a) thickness of Deccan traps, (b) thickness of Sediments below the traps and (c) the resistive basement depth. It is interesting to observe that sediment thickness decreases from north to south and increases from east to west. 


\subsection{Sediment Thickness Map}

Similar to the preparation of Deccan trap thickness map, the sediment thickness map has also been prepared and presented in Figure 9(b). As can be seen the sediment thickness is very thin towards the southern part of the study region and appears to be thicker towards the northeast and also the northwest of the study region. It is known from the geological studies that the Dhrangadhra and Wadhwan formations are exposed to the north and northeastern part of the study region. These sediments might have migrated towards the northwest through some transportation system, perhaps through Paleoriver channels.

\subsection{Basement Depth Map}

Similar to the trap and sedimentary thickness maps, the basement depth contour map of the study area has been prepared and presented in Figure 9(c).

As can be seen from the figure, basement depth is shallow towards the north and gradually decreases to very shallow $(1000 \mathrm{~m})$ and increases towards the south to a depth of about $3500 \mathrm{~m}$. Interestingly, towards the north western part of the study region, the basement depth is steeply dipping and increases to about $3.5 \mathrm{~km}$ and nearly oval-shaped depression in the basement can be clearly observed. The basement undulations might have played a key role in controlling the deposition of the sedimentary formations as well as the Deccan flood basalts. This can be understood more clearly from the 3-D representation of the basement depth map as described in the following.

\section{3-D Representation and Overlay of the Maps}

For better understanding of the distribution of the Deccan flood basalts, the sedimentary formations and the basement depth, a 3-D view (Figure 10) has been prepared. As can be seen from Figure 10, thick basalt cover exists towards the southeast corner and continues towards the west and extends up to the northwestern part by taking a turn from south to northwestern direction.

This can be visualized as thick lava flow from southeast to northwest and western direction. Similarly, the sedimentary formation looks like being migrated from north and northeastern direction towards west and northwestern direction. It is interesting to observe the deposition and solidification of Deccan traps and the sediment formations that look as if they are in opposite directions. It is interesting to observe the undulations of the basement depth. The basement depth has shown an upliftment near the centre of the region. This shallow basement depth is shown in blue color in the figure. This basement upliftment [7] [8] [9] might have played a crucial role in controlling the deposition pattern of both the Deccan traps as well as the Mesozoic sediments.

Additionally, it can also be understood that the upliftment of the basement might have taken place during Paleozoic times. This is so because the deposition pattern of the sediments and also the Deccan traps are distinctly different towards the south and north of the uplifted basement. 


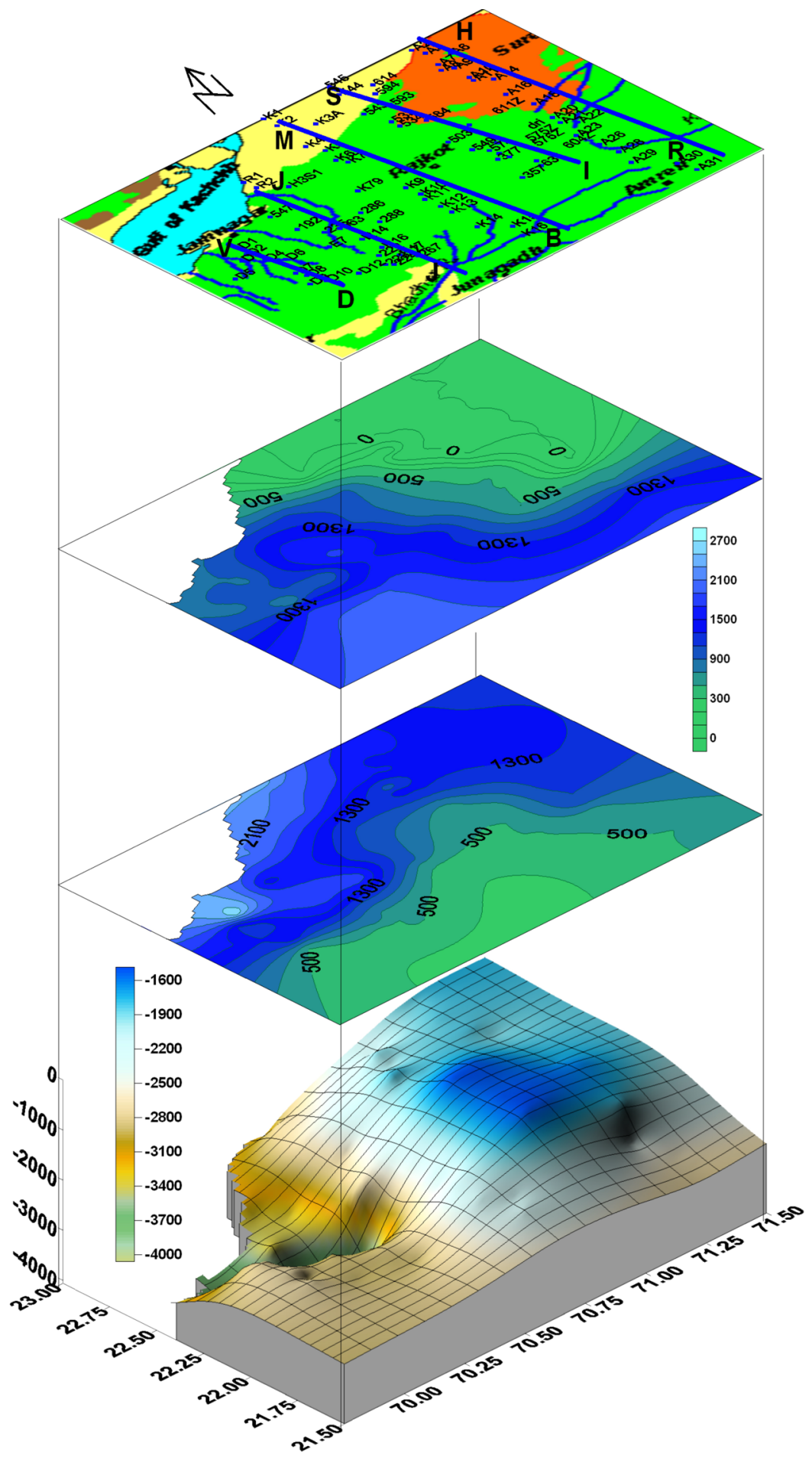

Figure 10. 3D view of the basement at the bottom of the figure and major geological units shown along with location map on the top. Shallow depth towards the east and deepening towards the west and north west can be observed.

\section{Gravity Modeling along Five Traverses}

\subsection{Gravity Modeling along HR Traverse}

Gravity variations along the traverse are good indicators for understanding the 
surface features. Short wavelength and long wavelength anomalies reflect the shallow and deeper features respectively. Majority of the sites along HR traverse fall in the zone of negative gravity as can be observed in Figure 2. Site A1 towards the north and A37 towards the south fall in positive gravity regions as can be observed from the figure. Bouguer gravity variations along the HR traverse are shown along with the derived geoelectric section in Figure 4. A gravity low is located at the center of the traverse as shown. WinGLink software has a forward modeling utility. Modeling of gravity for the 2-D geo-electric section has been carried out to bring out the subsurface in terms of reasonable layered density structure as shown in Figure 7. The inferred gravity values for traps, Meszoic sediments and basement are based on detailed gravity studies carried out by the gravity group of NGRI [10] [11]. Traps $(2.790 \mathrm{~g} / \mathrm{cc})$ are underlain by sediments $(2.350 \mathrm{~g} / \mathrm{cc})$ and high resistive basement $(2.900 \mathrm{~g} / \mathrm{cc})$. The underlying structure is an interplay of conductive ( $1, \mathrm{C} 2, \mathrm{C} 3$ and $\mathrm{C} 4)$ and resistive sections (R1, R2, R3 and R4) with Moho (30 - $32 \mathrm{~km})$. A good fit is observed between the computed and observed gravity for the assumed layered model for the deep structure from magnetotellurics.

\subsection{Gravity Modeling along the SI Traverse}

Bouguer gravity anomaly for the sites towards the north has higher values as compared to the sites towards the south as can be seen in Figure 5. The geoelectric section is characterized in terms of traps, sediments and high resistive basement. Density values for these formations have been evaluated from the gravity studies after the sample analysis from Lodhika bore well and characterization in the laboratory [10]. An upper density layer $(2.79 \mathrm{gm} / \mathrm{cc})$ corresponding to traps is followed by a sedimentary layer $(2.35 \mathrm{gm} / \mathrm{cc})$. This is underlain by consecutively increasing density layers, from $2.85 \mathrm{gm} / \mathrm{cc}$ (basement) to $3.3 \mathrm{gm} / \mathrm{cc}$ at lower mantle level.

Forward modeling of the Bouguer gravity anomaly, using the algorithm of Rodi and Mackey [12] and implemented on WinGLink platform is attempted here to understand the geoelectric section through layered structure. The eastern part is an uplifted region [8] as compared to the western region and Moho values of $32 \mathrm{~km}$ for the east have been used for the forward model. Figure 5 shows one such model where a good match between the observed and computed Bouguer values can be seen.

\subsection{Gravity Modeling along the Traverse MB Traverse}

Bouguer gravity variations for the sites along the $\mathrm{MB}$ traverse are plotted in Figure 6. As seen in the figure, gravity is high on the northern end at site K3A-K5 and gradually decreases to negative value of -15 at $\mathrm{K} 10$ and attains high (3 $\mathrm{mGal}$ ) on the extreme south end of the traverse. 2-D geoelectric section is conceived in the form of a layered structure as shown through forward gravity model in Figure 6. Moho values of $\sim 35 \mathrm{~km}$ have been considered in the model. Low 
gravity signatures $(-15 \mathrm{mGal})$ are observed at sites below $\mathrm{K} 79-\mathrm{K} 13$ in the middle of the traverse and probably correspond to the resistive block (R2) beneath the sites. Another low is also observed below the site K14 probably due to the high resistive block (R3) observed on the southern end of the traverse. A high observed at K12, K13 could be due to the fault (F3) between the sites K10 and K13. A high gravity region $(+12 \mathrm{mGal})$ is observed at sites $\mathrm{K} 3, \mathrm{~K} 4$ on the northern end and is likely due to the conductive fault structure (F1) between the sites K3A and $\mathrm{K} 5$ as well as the underlying conducive zone $\mathrm{C} 1$.

\subsection{Gravity Modeling along the Traverse JJ Traverse}

Bouguer gravity variations for the sites along the JJ traverse have been plotted as shown in Figure 7. The geoelectric section for the traverse can be interpreted in terms of a layered structure using 2.5-D gravity program on WinGLink platform. Different density values are ascribed to traps, sediments and basement, following calibration standards prescribed by the gravity group [10]. A forward gravity model for the geoelectric section can be seen in the Figure 7. A steady rise in gravity ( $-5 \mathrm{mGal}$ to $25 \mathrm{mGal}$ ) from the sites on the north to those on south is observed from the plot. A rising trend is observed at site R16, 222 till 267, probably due to the fault structure $\mathrm{F} 4$ and the conductive zone $\mathrm{C} 2$. One probable model is presented in Figure 7.

\subsection{Gravity Modeling along the Traverse VD Traverse}

Bouguer gravity variations for the sites along the traverse VD are plotted in Figure 8 along with the geoelectric section. A gradual rise in gravity value from -3 for the sites towards the north to positive values $(+30 \mathrm{mGal})$ for the sites towards the south is observed. MT site D12 is occupied over the plutonic mass or volcanic plug at Barda and hence has high positive Bouguer value. The conductive region at site at E7 is seen to contribute to the rising trend in Bouguer gravity value towards the southern end and this could be extended signatures for the observed volcanic plug at Barda or another possible buried volcanic plug at E7.

Another interesting comparison can be made between the seismic study and MT study from Lodhika borehole. Incidentally, a deep borehole exists near Lodhika and this location can be used as a calibration standard for testing various geophysical techniques. Two such attempts were made earlier from reinterpretation of the seismic data [13] [14]. From the reinterpretation of the seismic data, the existence of thin basaltic layer and another thin sedimentary layer just above the basement have been shown. However, from another study by Sain et al. the second thin sedimentary layer above the basement has been ruled out. Using joint inversion of the MT and deep resistivity sounding data, it is shown that joint inversion results showed a close match with the thickness of the Deccan traps and sedimentary formations. Geoelectric section along the MB traverse derived from MT studies near Lodhika well (K12) is presented in Figure 11 along with the results derived from seismic studies.

For comparison, a portion of the 2-D electric section near Lodhika borehole 
along with the results derived from seismics and borehole lithology can be seen from Figure 11. As can be seen from the figure, the results derived from 2-D geoelectric section shows a close match with borehole lithology.

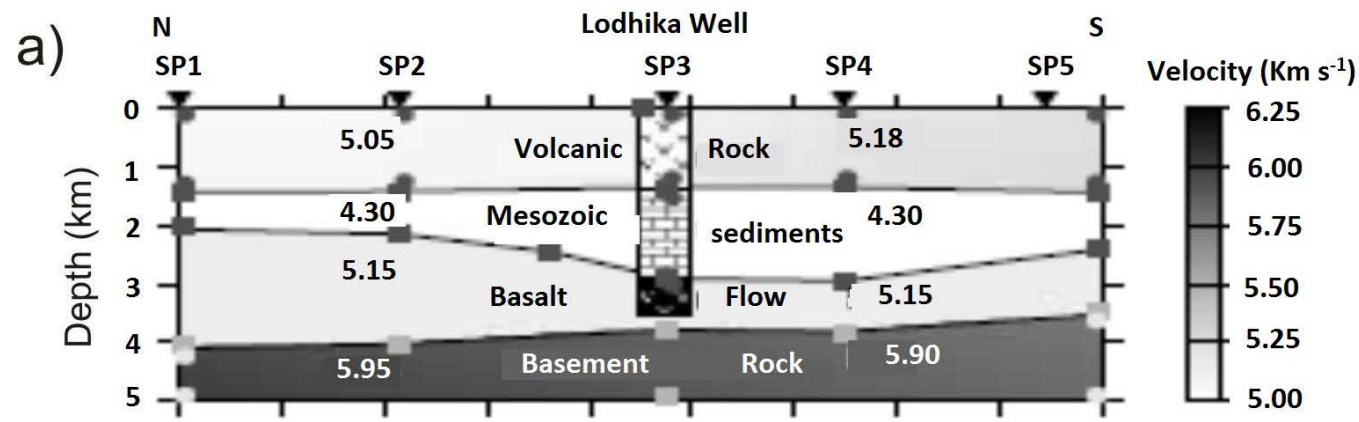

b)

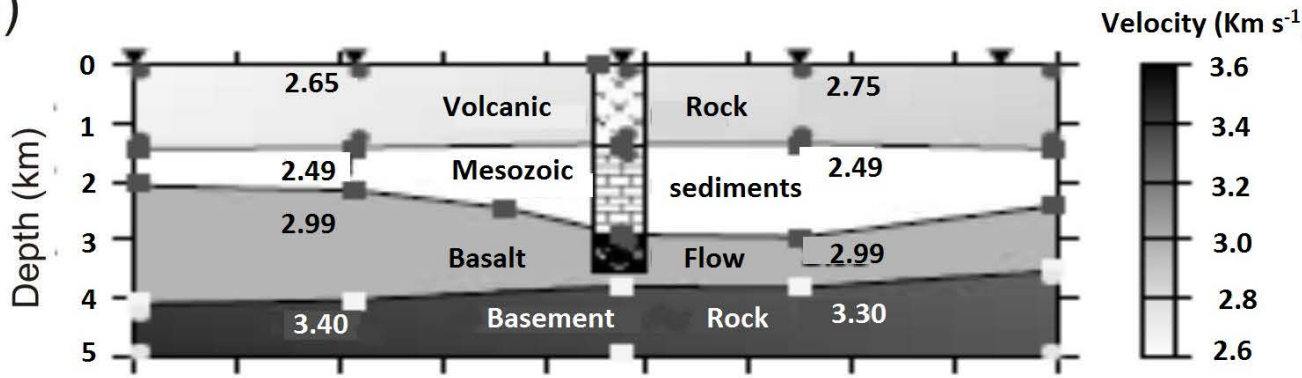

C)
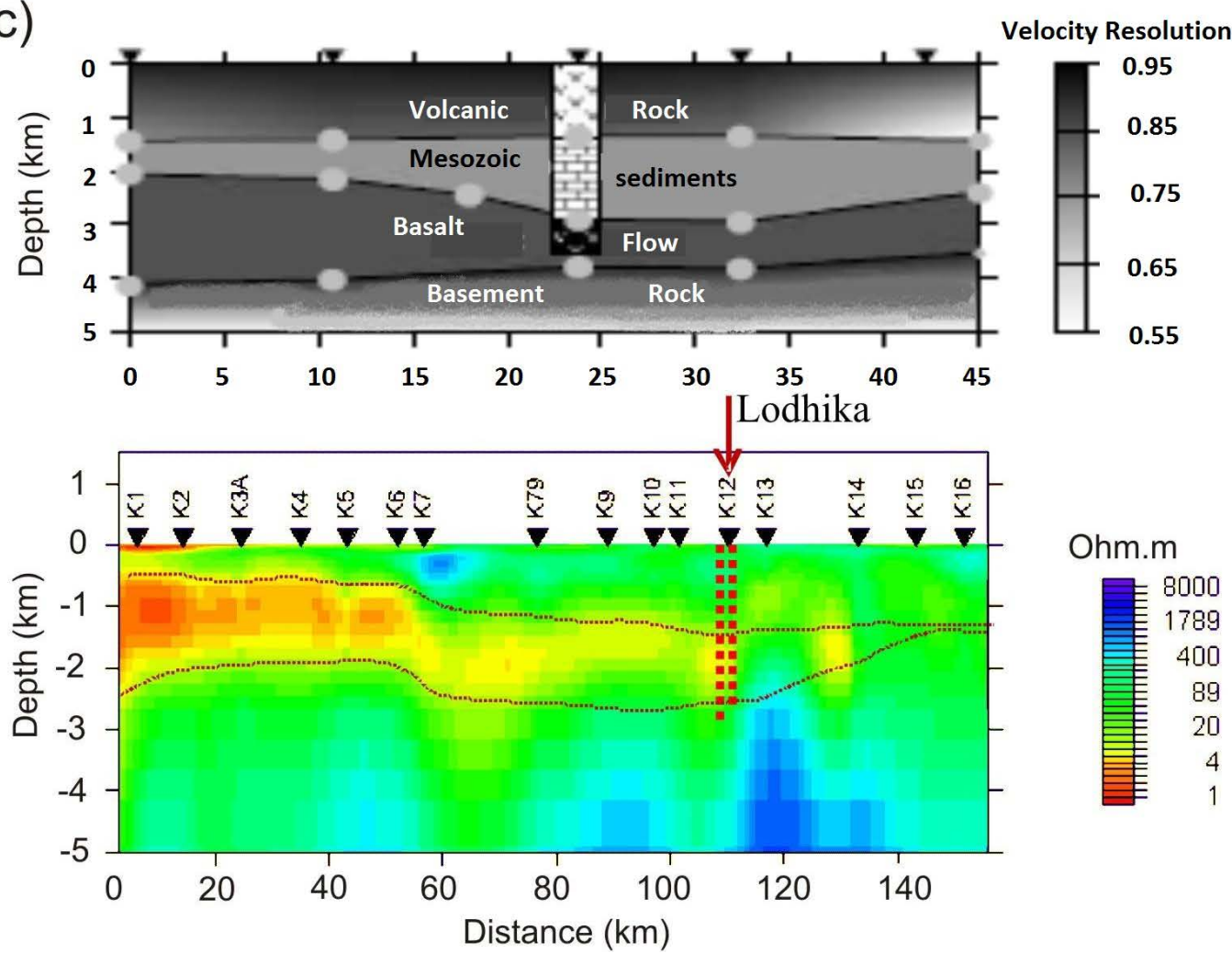

Figure 11. Good correlation of Seismic section (Kalachand et al., 2002) along with geoelectric section near bore hole drilled near Lodhika (K12) can be observed. Geoelectric section clearly indicates the presence of large thickness of sediments $(1.5-2 \mathrm{~km})$ towards the northern part and thinning towards the southern part can be seen. 


\section{Comparison of the MT Results with Seismicity of the Region}

It is interesting to study the seismicity of the Saurashtra region as intense seismic activity has been reported in Saurashtra region from the data observed for more than a decade. After the devastating Bhuj earthquake on $26^{\text {th }}$ January 2001, a major geophysical laboratory has been established in Gandhinagar to understand the earthquake phenomena of Kachchh and also other parts of Gujarat. The institute since its inception has established a number of seismic stations to monitor the seismicity of the Kachchh region and also the Saurashtra region. The network of observations made by this institute has helped to locate the earthquakes with greater precision of the epicentral locations of even micro-earthquake activity $(0.5-2.0 \mathrm{M})$. From the compilation of the seismic data observed over a period of nine years for Kachchh and Saurashtra region and also the adjoining regions, a map with epicenters for Saurashtra region has been prepared and is presented in Figure 12 [15]. From the figure, it can be seen that apart from intense seismic activity in Kachchh region, part of Saurashtra has also experienced microseismic activity with magnitudes of less than $5(M<5)$ during 2001-2009. The seismic activity in the Saurashtra region interestingly is seen concentrated in the form of three localized clusters A, B and C as shown in Figure 12. The cluster of seismic activity in the region A falls very close to the MT sites D5, D6, E7 and D7 along the VD traverse. The 2-D geoelectric section has clearly delineated this anomalous high conductivity structure extending from 20 $\mathrm{km}$ to about $40 \mathrm{~km}$. From the spatial correlation of anomalous high conductive

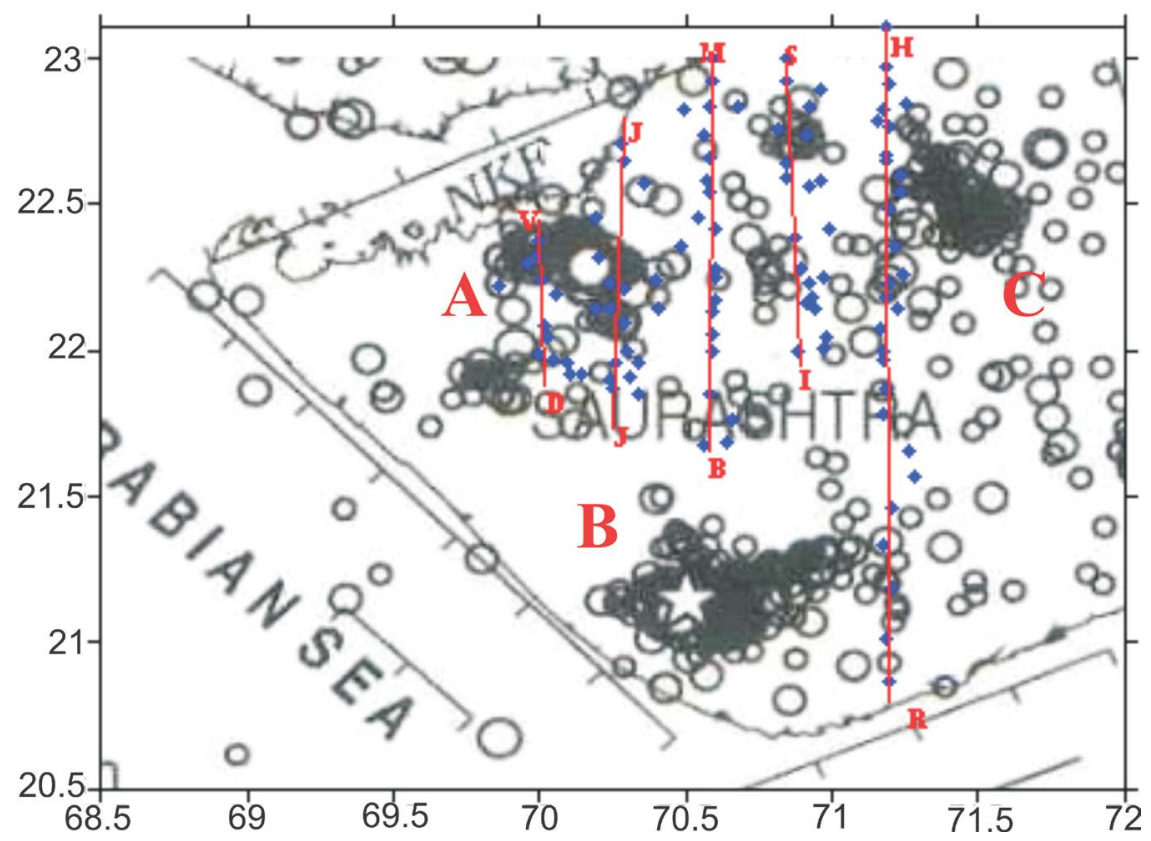

Figure 12. Earthquakes (2001-2009) epicentral map of Saurashtra region along with MT traverses can be seen. Anomalous conductor indicated in the form of an intrusive structure and the seismic clusters shown in the form of high seismicity indicating the reactivation of the structure at deeper depths. 
structure derived from MT data, the intense localized seismic activity is an interesting observation. Another interesting observation is a localized gravity high that also spatially has correlation with the localized seismic activity. From such a spatial correlation of the gravity high, anomalous high conductivity located at depth of $20 \mathrm{~km}$ and micro-seismic activity it can be conjectured that there is a movement between the anomalous conductive structure with respect to the surrounding rock matrix. It is not very clear as to whether another volcanic plug located at a depth of $20 \mathrm{~km}$ might be trying to reach the surface. From the correlation of high gravity and high conductivity one can visualize for a possible presence of the rock matrix in a fluid state that might have close association with basic magmas.

\section{Conclusions}

Based mainly on the five geoelectric sections derived from five magnetotelluric traverses in Saurashtra basin and joint interpretation along with gravity and seismic data, the following major conclusions can be drawn.

1) The results derived from the present study gave a new concept on the deposition of sedimentation and also the direction of the lava flow, apart from mapping the complex basement undulations. It has also provided evidence for crustal scale fault features, besides delineating anomalous conductive features. The results derived from the present study also gave a new concept on deep tectonic features as well.

2) The geoelectric section along the HR traverse has shown thick sediments towards north and thinning of the sediments towards south with sharp change of its thickness from the middle of the traverse, Jasdan (Figure 3(a)). Similar signatures of variation in the thickness of sediments are observed on all the five traverses (Figure 3).

3) The thickness of the Deccan traps along the HR traverse (Figure 3(a)) is thick towards south $(2000 \mathrm{~m})$ and thin towards north until the middle of the traverse and it becomes very thin or absent as we move further towards north. Similar signatures can be seen along MB, JJ and VD traverses. The trap thickness along the SI traverse is thin $(500 \mathrm{~m})$ as compared to the other four traverses.

4) The basement variation along HR traverse is about $1500 \mathrm{~m}$ towards northern part, sharply increasing to $2000 \mathrm{~m}$ in the middle of the traverse and gradually increases to about $2500 \mathrm{~m}$ towards the south. While such is the case along HR traverse, the basement depth gradually increases for other MT traverses as we proceed from HR traverse to VD traverse indicating that the basement depth increases from east to west.

5) A 3-D representation of basement depth and also from the thickness contour maps of sediment, Deccan traps have shown interesting features. From the basement depth map prepared for the northern part of the study region (Figure $3(\mathrm{c})$ ), two prominent structural features can be derived. Shallow basement towards the east with a depth range varying from $1500-2000 \mathrm{~m}$ with a nearly cir- 
cular shape feature, indicates a hill like structure buried below the study region. Another interesting feature is a sharp increase in basement depth towards the north-west of the study region with increasing basement depth reaching to as much as 3500 to $4000 \mathrm{~m}$. The thickness of the sediments (Figure 3(b)) is large $(1500$ to $3000 \mathrm{~m})$ towards the north and, north-east and north-west whereas it is thin $(<500 \mathrm{~m})$ in other parts of the region. The Deccan trap thickness is large $(1000-2000 \mathrm{~m})$ towards south and NW part of the study region, whereas it is thin towards other parts. From such a signature, it is very clear that the basement playing a key role in the deposition of the sediments is from north and flow of Deccan traps is from south.

6) Crustal scale faults extending from near surface up to mid crustal depths have been observed on all the five traverses. For example, five faults along HR traverse two faults along SI traverse, two faults along $\mathrm{MB}$, four faults along JJ, two faults along VD traverse. These faults are inferred based on steeply dipping anomalous conductive features in the upper crust, separated by resistive features depicting block structure.

7) Forward gravity modeling studies along the five traverses, by assigning the different density values for the resistive and anomalous conductive features have shown more confidence in the derived geoelectric sections. Some of the interesting features derived from gravity modeling studies and MT data are (a) deeper Moho near middle of the HR traverse (Figure 4, Figure 4(b)) undulating mid-crustal features along the four traverses SI, MB, JJ and VD (Figure 5, Figure 6, Figure 7 and Figure 8 respectively) (c) correlation of anomalous conductive features near the middle of the VD (Figure 8) traverse with gravity high and correlation of high resistive crustal block structure along VD traverse with gradual increase of gravity values from 0 to $30 \mathrm{mGals}$. From such a correlation of gravity and MT studies, in general, it can be conjectured that the anomalous high resistive features have exhibited more mafic and ultra-mafic rocks [16] [17].

8) The deep geoelctrical section with an inset for location of the five traverses is shown in Figures 4-8. High conductive features prominently observed as one moves from east to the northwest of the study region. The results have also given a reason for the seismicity clusters reported (Figure 12(a) and Figure 12(b)) in Saurashtra region during 2001-2009. The anomalous conductor in the form of an intrusive structure delineated along VD traverse at mid crust spatially correlates with high seismicity, indicating that the structure is probably reactivating. Projection of such intrusive structures on the surface can be considered as a possible location for future earthquakes.

\section{Acknowledgements}

We would like to thank the Director, CSIR-NGRI for his kind permission for publication of this study. This forms mainly from the Ph.D. thesis work of Dr.D. N. Murthy. His thesis was duly forwarded to the university by Director, NGRI 
for the award of his degree. We also wish to thank Dr. BPK Patro for discussions during various stages. We wish to thank the entire team of MTS group for their full cooperation during acquisition and processing of the data by Dr. D. N. Murthy.

\section{Conflicts of Interest}

The authors declare no conflicts of interest regarding the publication of this paper.

\section{References}

[1] Biswas, S.K. (1982) Rift Basins in the Western Margin of India and Their Hydrocarbon Prospects. AAPG Bulletin, 66, 1497-1513. https://doi.org/10.1306/03B5A976-16D1-11D7-8645000102C1865D

[2] Biswas, S.K. (1987) Regional Tectonic Framework, Structure and Evolution of the Western Marginal Basins of India. Tectonophysics, 135, 307-327. https://doi.org/10.1016/0040-1951(87)90115-6

[3] Courtillot, V.E. (1990) A Volcanic Eruption. Vigyan Scientific American, 1, 59-66.

[4] Duncan, R.A. and Pyle, D.G. (1988) Rapid Eruption of Deccan Flood Basalts at the Cretaceous-Tertiary Boundary. Nature, 333, 841-843. https://doi.org/10.1038/333841a0

[5] Veeraswamy, K. and Harainarayana, T. (2006) Electrical Signatures Due to Thermal Anomalies along Mobile Belts Reactivated by the Trail and Outburst of Mantle Plume: Evidences from the Indian Subcontinent. Journal of Applied Geophysics, 58, 313-320. https://doi.org/10.1016/j.jappgeo.2005.05.007

[6] Dhanunjaya Naidu, G. (2009) Magnetotelluric Study to Characterize Deep Geoelectric Structure of the Son-Narmada-Tapti Lineament Zone, Central India. PhD Thesis, Osmania University, Telangana.

[7] Kailasam, L.N. (1979) Plateau Uplift in Peninsular India. Tectonophysics, 61, 243-269. https://doi.org/10.1016/0040-1951(79)90300-7

[8] Surya Prakasa Rao, G. and Tewari, H.C. (2005) The Seismic Structure of the Saurahtra Crust in Northwest India and Its Relationship with the Reunion Plume. International Journal of Geophysics, 160, 318-330. https://doi.org/10.1111/j.1365-246X.2004.02448.x

[9] Tewari, H.C., Surya Prakasa Rao, G. and Rajendra Prasad, B. (2009) Uplifted Crust in Parts of Western India. Journal Geological Society of India, 73, 479-488. https://doi.org/10.1007/s12594-009-0033-9

[10] Sarma, S.V.S., Harinarayana, T., Someswara Rao, M., Virupakshi, G., Murthy, D.N., Sastry, R., Nandini, N., Sastry, T.S., Sarma, M.V.C., Madhusudan, R., Veeraswamy, K., Prabhakar, E., Rao, S., Lingiah, A., Srinivasulu, T., Patro, B.P.K., Manoj, C., et al. (1998) Integrated Geophysical Studies for Hydrocarbon Exploration, Saurashtra Region, India. NGRI Tech. Report, No. NGRI-98-EXP-237.

[11] Tiwari, V.M., Vyaghraswara Rao, M.B.S. and Mishra, D.C. (2001) Density Inhomogeneties beneath Deccan Volcanic Province, India as Derived from Gravity Data. Journal of Geodynamics, 31, 1-17. https://doi.org/10.1016/S0264-3707(00)00015-6

[12] Rodi, W. and Mackey, R.L. (2001) Nonlinear Conjugate Gradients Algorithm for 2D Magnetotelluric Inversions. Geophysics, 66, 174-187.

https://doi.org/10.1190/1.1444893 
[13] Dixit, M.M., Satyavani, N., Sarkar, D., Khare, P. and Reddy, P.R. (2000) Velocity Inversion in Threlodhika Area, Saurashtra Peninsula, Western India. First Break, 18, 499-504. https://doi.org/10.1046/j.1365-2397.2000.00109.x

[14] Kalachand, S., Colin, A.Z. and Reddy, P.R. (2002) Imaging of Subvolcanic Mesozoics in the Saurashtra Peninsuls of India Using Travel Time Inversion of Wide-Angle Seismic Data. Geophysical Journal International, 150, 820-826. https://doi.org/10.1046/j.1365-246X.2002.01749.x

[15] Girish (2011) International Symposium on the 2001 Bhuj Earthquake and Advances in Earthquake Science AES 2011 (22-24 January, 2011 at Institute of Seismological Research, Raisan, Gandhinagar, Gujarat, India), Understanding Earthbeats, 06-07.

[16] Deshmukh, S.S. and Sehagal, M.N. (1988) Mafic Dyke Swarms in Deccan Volcanic Province of Madhya Pradesh and Maharashtra. In: Subbarao, K.V., Ed., Deccan Flood Basalts, No. 10, Geological Society of India, Bangalore, 323-340.

[17] Deshmukh, S.S. (1988) Paleomagnetic Variations in Compound Flows of Deccan Traps and Their Significance. In: Subbarao, K.V., Ed., Deccan Flood Basalts, No. 10, Geological Society of India, Bangalore, 305-319. 